\title{
SOCIO-TECHNICAL INTEGRATION RESEARCH IN AN EASTERN EUROPEAN SETTING: DISTINCT FEATURES, CHALLENGES AND OPPORTUNITIES
}

\author{
MIKLÓS LUKOVICS ${ }^{1,2}$ - ERIK FISHER ${ }^{2}$ \\ ${ }^{1}$ Faculty of Economics and Business Administration, University of Szeged, Szeged, Hungary \\ Email: miki@eco.u-szeged.hu \\ ${ }^{2}$ School for the Future of Innovation in Society, Arizona State University, Tempe, AZ, USA \\ Email: efisher1@asu.edu
}

\begin{abstract}
While technological innovation is a core element of efforts to increase public welfare, innovators are rarely trained to take the societal dimensions of innovation into account in a systematic manner. Responsible innovation has emerged within policy discourses worldwide to address this challenge. Implementing responsible innovation in daily practices, however, requires addressing both the multidisciplinary and the culturally situated nature of innovation processes. Effectiveness of Socio-Technical Integration Research (STIR) has been tested, but primarily only in developed countries, raising questions about how well it works in innovation and cultural settings differing from Western cultures. Therefore, this study analyzes the possibities of institutionalizing responsible innovation in an Eastern European country, namely in Hungary. For this investigation, we conducted STIR-pilots in two Hungarian natural science research groups. The findings show that though the original STIR method can be adapted to support responsible innovation practices in Hungary, the differences in the innovation environment and culture (such as grant-driven innovation; lack of trust; less knowledge on responsible innovation; lack of law on the societical impacts of research and innovaton) require methodological modifications in order to improve STIR's effectiveness.
\end{abstract}

Keywords: responsible research and innovation, socio-technical integration research, Hungary JEL-codes: O32, O35 


\section{INTRODUCTION}

Science-based technological innovation is essential for improving competitiveness of both firms and territorial units (regions, countries, integrations) (Apak Atay 2015; Ciocanel - Pavelescu 2015; Dosi et al. 2015; Edquist 2005; Zouaghi - Sánchez 2016). At the same time, technological and scientific advances often come at the cost of undesirable societal outcomes. For instance, technological improvement may result in growing demand for machinery and less need for human workers in a firm, thus contributing to jobless growth, a phenomenon that has been recently observed in the United States (Martus 2015). Furthermore, genetically modified organisms (GMO) continue to be strongly debated worldwide (Aerni 2005; Lopez - Carrau 2002; Nielsen et al. 2003; Vigani et al. 2010). Other inventions (e.g. smart phones, CFC gas) and research (e.g. nuclear chain reaction and animal experiments in cosmetics or pharma industry) are also examples of the necessity to take the broader (social, ethical and environmental) effects of research and innovation processes into consideration. This tension in turn contributes to public distrust of and ambivalence towards science and innovation: according to a Eurobarometer (2013) survey, while $77 \%$ of respondents indicated that science and technology has - very $(60 \%)$ or fairly $(17 \%)$ - positive societal impacts, around $60 \%$ of the respondents indicated that science and technology has negative side-effects to human life and environment. At the same time, the survey did not show significant differences across the countries. In Hungary - the country which stands in the focus of the present study $-73 \%$ of the respondents indicated that science and technology have positive impact on the society, while only $13 \%$ claimed the negative impacts.

As investment in science and innovation increase worldwide, it stands to reason that managing the unavoidable tension between risks and benefits is not only a question of public relations; it is in fact one of the grand challenges our society is presently facing (Guston 2014). One response to this challenge is suggested in the idea of responsible research and innovation (RRI). In a relatively short period of time, RRI has been buttressed by a sizable body of research that has produced rationales, definitions, elements, key factors, dimensions and frameworks. The challenge of implementating RRI requires not only theoretical but also empirical research into the conditions that govern innovation practices and that can enable them to be more responsive to societal concerns and considerations. One particular mechanism for strengthening science-society relations that has recently been mandated in high-level polices around the world is the integration of social scientific and natural scientific research (Bennet - Sarewitz 2006; Macnaghten et al. 2005; Rodriguez et al. 2013). Given that RRI implementation is an extremely new and emerging topic in both academic and practitioner cir- 
cles, such integration represents a value-added approach to enhance capacities for identifying opportunities for making practical adjustments to research and innovation trajectories that are geared to addressing societal contexts. SocioTechnical Integration Research (STIR) was initially designed to assess the capacity of scientific and engineering laboratories to perform this type of integration (Fisher 2007) and has since become an established method upon which RRI concepts and practices are based (Owen et al. 2012; Stilgoe et al. 2013; von Schomberg 2012).

Meanwhile, the topic of RRI is a relatively unfamiliar concept for transition economies and studies on the implementation of RRI concentrate on developed countries. Thus, we are motivated by the question of whether and how RRI can be incorporated into Eastern European settings and we investigate this broader question in the more specific instance of piloting STIR within Hungarian laboratories. The structure of the paper is as follows. We first introduce responsible research and innovation and provide a brief literature review. Following this, we describe the implementation of STIR in research groups. Finally, we present our empirical results and discuss the findings in relation to the broader questions that motivate this study.

\section{RESPONSIBLE RESEARCH AND INNOVATION}

Given the large investments of national governments and private firms in research and innovation, it is not surprising that there is also increasing recognition of the possibilities for unintended consequences of these activities. Specifically, both scholars and policy makers have called for more reflective and anticipatory roles for a broad set of actors so that the purposes, motivations and possible yet uncertain ramifications of innovation are taken into account early on and in a way that informs practical and ongoing decision-making (Barben et al. 2008; Guston - Sarewitz 2002). The concept of responsible research and innovation (RRI) is one attempt to respond to such calls.

Even as the concept of RRI was still emerging, a central theme has been that of interdisciplinary collaboration between social and natural scientists and engineers in order to enhance research and innovation practices in a broad societal context (Fisher et al. 2006). Such socio-technical integration is one of a handful of RRI themes that have been identified within academic discourse, and it has been specifically linked to the desired qualities of reflexivity and responsiveness (Fisher - Maricle 2014; Owen et al. 2009; Sutcliffe 2011; Stilgoe et al. 2013; Taebi et al. 2014). Several definitions of RRI have been offered in the past few years, which point out many aspects of the phenomenon (thus its multi- and interdisciplinarity) 
(Buzás - Lukovics 2015; Sutcliffe 2013; Chorus et al. 2012; Tihon - Ingham 2011; Rip 2005; Owen et al. 2012). The scientific community bases its work most frequently on the definition of von Schomberg (2012: 9): “A transparent, interactive process by which societal actors and innovators become mutually responsive to each other with a view to the (ethical) acceptability, sustainability and societal desirability of the innovation process and its marketable products (in order to allow a proper embedding of scientific and technological advances in our society)." We also rely on this definition during our research work. Besides responsible research and innovation, the concept of responsible innovation (RI) also exists. We can make small distinctions between them: RI is in the focus of scholarly work (see, e.g., Owen et al. 2009 or Stilgoe et al. 2013), whereas RRI is still a bureaucratic and policy term. Since both RI and RRI seem to include a range of research and innovation activities, they refer to what is captured by the term "techno-science." As a result, in this paper our use of the concept RRI takes into account that it includes not only innovations but the research activities behind them.

If RRI is taken into account in the daily decisions of the entire innovation pipeline, (civil) society and the research community may have a closer relationship and the final outcome of the research process would be a more socially desirable innovation. For instance, the chemical industry in Hungary has a bad reputation because people think of its environmental pollution and hazardous manner, and the risks of its production (Várady et al. 2005), however, it is difficult for citizens to discuss chemical products in precise language (Eurobarometer 2011). That is, people often form opinions without reliable knowledge or information. This is suggested by the fact that citizens feel that they receive moderate information on the risks of chemical production (Eurobarometer 2011). If there were more dialogues between the society and the chemical industry (including its research department), this kind of oppose possibly decreased. The RRI has this kind of aim, too and may respond to these challenges.

In order to institutionalize the RRI concept, a number of studies on socio-technical integration have already been conducted (e.g. Fisher et al. 2015; Flipse et al. 2013; Flipse et al. 2014; Flipse et el. 2015; Panzda - Ellwood 2013; Ravesteijn et al. 2015). These investigate how to incorporate responsibility in innovation process in different research groups in both academic and industrial settings. But most of the current studies on RRI concentrate on developed countries. Nevertheless, some findings of researches conducted in developing countries (e.g. Indonesia, Viet Nam) prove that the culture with social and political context, where the RRI is planned to be integrated into the innovation process, has to be taken into account (Macnaghten et al. 2014; Setiawan - Singh 2015; Voeten et al. 2015). It is argued that the concept of RRI was developed in a modern and developed (in- 
novation) environment, therefore it may work differently in a different culture. Although Hungary has already joined the European Union, the Hungarian culture and economic background differs from the Western countries: for instance, there is a special form of capitalism in the Central and Eastern European (CEE) member states (Farkas 2011). ${ }^{1}$ In addition, Lukovics et al. (2016a) showed that in CEE countries innovation itself is differently defined which also influences the adoption of RRI. In comparison with the OECD countries, the expenditure on research and development in Hungary is relatively low (only $42 \%$ of the OECD average), while the per capita expenditure is only $25 \%$ of the OECD average (Havas Nyíri 2007). Regarding the European Innovation Scoreboard, Hungary belongs to the moderate innovation countries (EC 2016), and innovation is uneven across the Hungarian regions (Lengyel - Leydesdorff 2011): Budapest and its surroundings are the dominant engine for the innovation performance; the North-Western part of Hungary could join the neighboring countries' innovation systems; while the southern part of Hungary still has an old-fashioned innovation system, which is mainly controlled by government spending. We also found that the Hungarian Act on Research and Development, Technology and Innovation does not deal with any social or ethical issues. By contrast, for instance, the Dutch Higher Education and Research Act and the Research and Development Promotion Act have social and ethical relations. Furthermore, the Netherlands Organisation for Scientific Research issued a large number of RRI calls, whereas the Hungarian National Research, Development and Innovation Office has not published anything about RRI yet. All these issues prove that the awareness of RRI in Hungary completely differs from that of Western countries.

While there are several proposed and established methods for enhancing societal responsiveness through the introduction of socio-technical integration within the innovation process (e.g., Fisher et al. 2015), we focus on Socio-Technical Integration Research (STIR). STIR involves a structured approach that has been employed in over three-dozen research and innovation settings and has documented results in a number of national settings across Europe, North America and Asia (Fisher - Schuurbiers 2013). Building upon this relatively broad and comparative basis, we investigate the extent to which STIR, as an indicator of RRI more generally, can be adopted in transition countries located in Central and Eastern Europe. This investigation is necessary because - as we mentioned above - the awareness of RRI is completely different in Western and Central European countries, and since the starting point is different, the STIR method should be somehow adjusted to these different circumstances. 


\section{STIR OVERVIEW AND RESULTS IN DEVELOPED COUNTRIES}

STIR supports interactions between experts from different disciplines (humanities and social science with technological sectors), who collaboratively reflect on the societal context of research decisions in order to support reflexive learning and practical adjustments (Fisher - Schuurbiers 2013). In the selection phase of STIR, the STIR investigator (hereafter, "investigator") identifies one or more research settings, typically laboratories, to become embedded in and work as a participant-observer. In an invitation letter, the heads of research groups are asked for their own or their delegates' participation in the research. In this phase, the principal investigator (PI) decides whether or not to allow an investigator to join his or her laboratory for 12 weeks. Once the PI accepts, then the investigator solicits researchers from the group who are willing to actively participate in the collaborative activities (as "high interaction" persons) and also researchers who remain so-called "no interaction" persons (or "controls"). The investigator will be in active contact with the high interaction researchers. The controls allow the investigator to analyze whether any enhancements of the decision practices are the result of STIR interactions and exercises or other factors such as lab culture. While the specific study objectives may set requirements for who is recruited to participate, participation ultimately depends on the voluntary choice of the researchers, who are not compensated for their participation and who may opt out at any time.

During the implementation, the STIR investigator is embedded in the daily practices and operations of the natural science research group. This may entail taking equipment training classes, attending research meetings, and joining specific research projects. The interactions conducted with the research participants consist of the following elements: pre-study interview, post-study interview, participant observation, and regular application of a decision protocol (Fisher 2006). During the pre- and post-study interviews, the investigator asks the same questions of all participants in order to establish baselines and track traceable changes. The open interview questions aim to investigate whether and how interdisciplinary interactions may help enhance the integration of social and ethical considerations into research decisions. The pre-study interview is the beginning of the participant-observation at the same time, during which the investigator visits the laboratory multiple times a week for 12 weeks and monitors the research activity of the participants recognizing their activity, attitude and decision points through the continuous interactions. The investigator communicates with the high interaction researchers while there is little to no contact with the controls.

In order to facilitate high-impact, real-time reflection on the evolving research activities, and to track the ongoing attitudes and behaviors of the researchers 
participating in STIR, a "decision protocol" is regularly deployed throughout the duration of a STIR study (Fisher 2007; Fisher et al. 2006; Schuurbiers - Fisher 2009). The protocol is based on a four-fold model of decisions that includes opportunity, considerations, alternatives and outcomes. With the assistance of the protocol, investigators and participants collaborate to identify and map out the distinct decision components that lead to any given decision, through a collaborative process of co-description, where decisions are observed, described, and reflected upon. Therefore, investigators ideally become involved in the decisions and strategies even though they begin as merely observers (Schuurbiers 2011). The protocol is usually deployed as a "grid" using a sheet of paper with four quadrants, one for each component. This facilitates the collaborators to write down and even hand-draw material together, in a transparent and interactive manner.

Regular deployment of the protocol is theorized to effect midstream modulation, in which participants become more aware of and responsive to the societal context of their technical decisions. This consists of three stages: de facto interactions between societal and technical factors of research decisions; reflexive awareness of these interactions in real-time; and deliberate modulation of the evolving decision pathways. The three primary outcomes of interest are derived from this analytical framework of midstream modulation. They consist of reflexive learning, value deliberations, and practical adjustments.

Investigators document these outcomes both quantitatively and qualitatively. They assemble qualitative accounts in both narrative and tabular form, depending on which are salient and relevant to the research questions and objectives. There are two choices for data presentation about the STIR protocol exercises and observations: narratives ("stories") and tables. As a result, the deliberate modulations made by the research participants are correlated to the deployment of the protocol and to the specific features of the innovation environment and process already operating at the level of daily decisions. Reflexive learning is theorized to enhance researcher capacities to make decisions that are consciously compatible with RRI objectives and principles.

STIR has been used in several different types of research and innovation organizational settings, from university labs working on nanotechnology, synthetic, neuroscience and genetics to industrial labs working on biotechnology, microelectronics and nano-materials. In the vast majority of cases where the protocol was used to structure collaborative inquiry, all three outcomes are observed and laboratory participants see these developments as valuable for their own research (e.g., Fisher et al. 2010; Flipse et al. 2013; Schuurbiers 2011).

Altogether STIR is not only a method for socio-techno integration, but it also enables capacity building for institutionalizing RRI: the output of STIR claims not only the changes in behavior, but also the learning and/or understanding that 
can lead to more changes in behavior later on. In theory, there are at least three potential outcomes from STIR studies: (i) skill development, learning, human capital; (ii) changed behaviors, practices, design and research pathways; and (iii) increased trust and social capital between different (social science and natural science) disciplines.

STIR was applied in developed countries (e.g., the United States, the Netherlands, Denmark, the United Kingdom, Spain, and Belgium), but - as we emphasized - the Hungarian innovation environment and conditions are different from those of the developed countries, ${ }^{2}$ which influence the awareness and attitudes of researchers on and towards RRI. Since the justification of RRI is different in these cultures, we had to pay attention to these issues in the STIR pilots. The main differences are the following. First, STIR has been used in countries which all belong to the 'innovation leader' or 'innovation follower' countries according to the European Innovation Scoreboard, while Hungary is a moderate innovator country (EC 2016). Second, since trust among partners is crucial concerning the performance of research and development (Bien et al. 2014), the relatively low level of trust in each other amongst the Hungarian people may have huge impact on the success of STIR. ${ }^{3}$ Third, Hungarian researchers and actors in the innovation process have minimal information on RRI in general (Lukovics et al. 2016b), while in other countries - for instance - the official regulation on research and innovation pays attention to the criterion of responsibility. Fourth, in Hungary it is not usual to engage the public in policy making, therefore the role of society in science is sill "in its infancy" (Inzelt - Csonka 2014: 60).

\section{STIR IN HUNGARY - PILOT PROJECT}

In order to show how STIR can be implemented in research groups working in a relatively underdeveloped country, we chose Hungary as a sample country. Hungary is a transition country in Central and Eastern Europe (CEE). These countries have special features, as Lukovics et al. (2016b) discovered: small territorial size; low GDP/capita; extremely little investment of public and private funds into research and development; "grant-driven" innovation paradox is a feature meaning that innovation is conducted if there are available financial resources; strong role of

2 This difference also can be measured by the ranks in the Global Competitiveness Report, published by the World Economic Forum.

3 The OECD measures trust and social cohesion regularly: according to the trust indicator published in the 2011 survey (OECD 2011), 80\% of the people express high level of trust in each other in the Netherlands, while in Hungary, only $47 \%$ of the people do. The Hungarian value is not only lower than the value of the Netherlands, but it is also below the OECD average (59\%). 
informal and indirect relationship between stakeholders; corruption; strong political influence on innovation activities; high territorial concentration of innovation activities; and missing high-developed R\&D infrastructure and technology transfer.

\subsection{Local environment of the STIR}

We implemented the STIR method in two research groups working in Szeged in Hungary. Szeged is Hungary's fourth most densely populated city and it is the center of both the Southern Great Plain region and Csongrád county. The GDP per capita on purchasing power parity of both the region and the county is far behind the EU average and varied between $45-50 \%$ thereof in 2013, and economic growth after Hungary's accession to the EU in 2004 has remained minimal. The employment rate in the region is also significantly lower than the EU average, and it falls below the Hungarian average, too. In the majority of figures related to research and development, however, the Southern Great Plain has a strong position achieving second place in the ranking of Hungarian regions. Csongrád county, in turn, is in an even better position, since in the majority of R\&D input and output figures it ranks first among the counties. Indeed, the specific number of those with an academic degree (35 persons per 10,000 inhabitants) is higher than in Central Hungary (29 persons per 10,000 inhabitants) in 2015, which belongs to the developed regions, and the proportion of those with tertiary education is close to the EU average.

The tertiary education sector and knowledge-intensive service providing activities are mainly connected to the University of Szeged, which is one of the top quality universities of Eastern Europe according to international rankings (Lengyel 2009). The University of Szeged is the largest employer in the region with its approximately 7 thousand employees; it has 27 thousand university students studying at 12 faculties and 6-7 thousand students graduate there each year. Some 130 departments operate in a wide field of disciplines and the university has 770 professor-researchers with an academic degree. 8-900 PhD students study at the 19 doctoral schools, and the university has a significant international relationship network and an extended university-industry relationship system (Vilmányi 2011). One of the EU's scientific flagship initiatives, the Extreme Light Infrastructure-Attosecond Light Pulse Source (ELI-ALPS), is being built in Szeged.

Altogether, Szeged is located in a "lagging behind" region with outstanding innovation activities. The explanation for this paradoxical situation is that the local economy is unable to adequately to exploit the innovation results produced by the University of Szeged locally, and the local enterprises are not able to utilize these pioneering innovation results, thus these results are utilized outside of the region. 
Most of the special features relevant to innovation environment that are typical of CEE countries described earlier prevail in this region.

\subsection{Selection of the research group}

During our research, we followed the original STIR methodology and logic introduced in Section 3, however, the process was streamlined slightly in the following way: after the PI agreed to participate (in the selection phase), the PI was also asked to nominate high-interaction and no-interaction researchers from the group. Figure 1 depicts the overall logic of this method as used for our Hungarian pilots.

As in the developed country studies, we sent the invitation letter to 15 research groups of natural sciences working at the University of Szeged, but the response rate was low: only 4 research groups responded, out of which only one researcher undertook one single interview. Out of the other 3 respondents one person rejected, while another one partly accepted the invitation by delegating a colleague

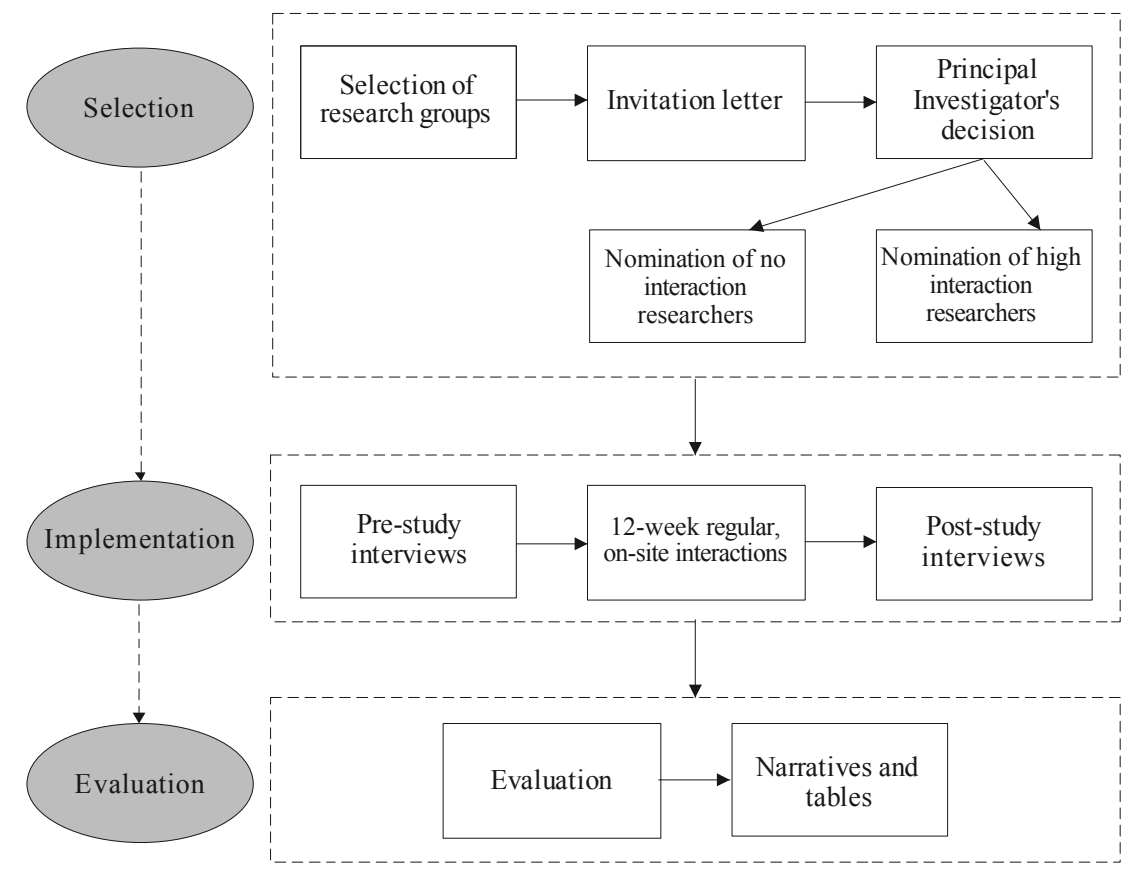

Figure 1. Logic of STIR piloted in Hungary

Source: authors 
to the interview, and the third one also rejected it, but proposed other researchers who might be asked in this topic. This unsuccessful invitation can be traced back to the lack of confidence (Lukovics et al. 2016a). This fact did not interfere with the current pilot research, since based on our previous statement, the relevance of personal, informal relations are strongly overrepresented compared to developed countries (Lukovics et al 2016a).

After the initial failure of the invitation letters, we selected a research department from our own relationship network. It is a key aspect that though the research group involved in our research is based at the University of Szeged and works in academic circumstances but the group has been granted by the Hungarian Academy of Sciences through a research program (Lendület program) that provides predictable grant and excellent infrastructure for world-class researches. This financial assistance ensures better and more predictable working environment for this research group, since they can be independent from the bureaucracy of the University of Szeged. From our point of view, a Hungarian Lendület research group would mean a transition between the innovation environment of developed and underdeveloped countries, thus it provides an optimal pilot environment for testing the effectiveness of the STIR methodology in a completely foreign environment (the innovation environment of a transition country).

Table 1. Research participant profiles

\begin{tabular}{|c|c|c|c|c|c|c|}
\hline \multicolumn{2}{|c|}{$\begin{array}{l}\text { Partici- } \\
\text { pant }\end{array}$} & \multirow{2}{*}{$\begin{array}{l}\text { Status } \\
\text { PhD } \\
\text { student }\end{array}$} & \multirow{2}{*}{ 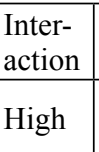 } & \multirow{2}{*}{$\begin{array}{l}\text { Research area } \\
\text { Epilepsy (electronic } \\
\text { stimulus of brain) }\end{array}$} & \multirow{3}{*}{$\begin{array}{l}\text { Research group } \\
\text { Oscillatory } \\
\text { Neuronal Networks } \\
\text { Research Group } \\
\text { in the Department } \\
\text { of Psychology of } \\
\text { Faculty of Medicine }\end{array}$} & \multirow{2}{*}{$\begin{array}{l}\text { STIR-period } \\
\text { September- } \\
\text { November } 2015\end{array}$} \\
\hline \multirow{4}{*}{$\stackrel{\vec{E}}{\infty}$} & P1 & & & & & \\
\hline & $\mathrm{P} 2$ & $\begin{array}{l}\text { PhD } \\
\text { student }\end{array}$ & High & $\begin{array}{l}\text { Epilepsy (long-term } \\
\text { electronic stimulus } \\
\text { of brain) }\end{array}$ & & \\
\hline & P3 & $\begin{array}{l}\text { PhD } \\
\text { student }\end{array}$ & No & Vision & & \\
\hline & P4 & $\begin{array}{l}\text { PhD } \\
\text { student }\end{array}$ & No & Neuropsychology & & \\
\hline \multirow{4}{*}{ 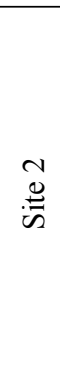 } & P5 & $\begin{array}{l}\mathrm{PhD} \\
\text { student }\end{array}$ & High & $\begin{array}{l}\text { Carbon dioxide } \\
\text { reduction on conduc- } \\
\text { tive polymers }\end{array}$ & \multirow{4}{*}{$\begin{array}{l}\text { Photoelectrochemi- } \\
\text { cal Research Group, } \\
\text { in the Department } \\
\text { of Physical Chem- } \\
\text { istry and Materials } \\
\text { Science of Faculty } \\
\text { of Science and Infor- } \\
\text { matics }\end{array}$} & \multirow[t]{4}{*}{$\begin{array}{l}\text { December } 2015- \\
\text { February } 2016\end{array}$} \\
\hline & P6 & $\begin{array}{l}\text { Post- } \\
\text { doctoral }\end{array}$ & High & $\begin{array}{l}\text { Carbon dioxide re- } \\
\text { duction on graphene }\end{array}$ & & \\
\hline & P7 & $\begin{array}{l}\mathrm{PhD} \\
\text { student }\end{array}$ & No & $\begin{array}{l}\text { Diffusion rate in } \\
\text { several materials }\end{array}$ & & \\
\hline & P8 & $\begin{array}{l}\text { PhD } \\
\text { student }\end{array}$ & No & $\begin{array}{l}\text { Patterns on rocks and } \\
\text { on animal integu- } \\
\text { ments }\end{array}$ & & \\
\hline
\end{tabular}

Source: authors 
As a result, the current Eastern-European STIR pilot describes two laboratory engagements in two sites at the University of Szeged and eight laboratory researchers participated in the study (four in Site 1, marked as P1-P4; and four in Site 2 marked as P5-P8), out of which four people were high interaction persons (P1, P2, P5 and P6) and the other four were no interaction persons (P3, P4, P7 and $\mathrm{P} 8$ ) (Table 1). As discussed in Chapter 3, the controls were only pre- and poststudy interviewed at the beginning and at the end of the research.

The STIR investigator was an economist, with specialization in responsible innovation, therefore being aware of the elements, layers and keys of it, and at the same time having economic dispositions in his thinking. The investigator was trained in the United States to use the method; additionally, the investigator interviewed other former social science STIR investigators and natural science participants in previous STIR studies in the interest of the comparability of results.

Methodologically, the piloting was conducted in a way that the investigator was embedded for 12 weeks in the operation of each of the research groups in the field of natural science and examined the adaptability of the STIR tool in daily operation, under natural conditions. During the 12 weeks at each site, we conducted continuous interactions with four of the researchers (high interaction persons), the other four persons (no interaction persons) operated as a control group. The preand post-study interview questions covered mainly the scientific research area, qualification and knowledge in the field of responsible innovation of the participating researchers, their opinion and view about the Hungarian innovation process. The evaluation of the social, ethical, environmental, etc. dimensions of responsible innovation and the definition of the related activities also played a role in the frame of the interview. Subsequently, our questions covered a number of topics, among others questions in relation with the chosen realization method of the participant's

Table 2. Methodological overview of the SEE STIR pilot program

\begin{tabular}{l|l|l|l}
\hline & \multicolumn{1}{|c|}{ Week 1 } & \multicolumn{1}{c}{ Week 2-11 } & \multicolumn{1}{c}{ Week 12 } \\
\hline Activity & Pre-study interview & Weekly observations & Post-study interview \\
\hline Tool & Interview guide & $\begin{array}{l}\text { Decision protocol with } \\
\text { decision components } \\
\text { (modulators) }\end{array}$ & Interview guide \\
\hline Purpose & $\begin{array}{l}\text { To understand the research } \\
\text { activity of the researchers; } \\
\text { and to establish baselines } \\
\text { for participants' attitudes } \\
\text { towards dimensions of } \\
\text { RRI and their level of } \\
\text { reflexive awareness at the } \\
\text { beginning of the study }\end{array}$ & $\begin{array}{l}\text { Identification and } \\
\text { discussion of decision } \\
\text { modulators; monitoring } \\
\text { of de facto, reflexive and } \\
\text { deliberative modulation, } \\
\text { and understanding of } \\
\text { notions concerning RRI } \\
\text { keys and dimensions }\end{array}$ & $\begin{array}{l}\text { To measure changes in } \\
\text { participants' attitudes } \\
\text { towards dimensions of } \\
\text { RRI and/or in their level of } \\
\text { reflexive awareness at the } \\
\text { end of the study }\end{array}$ \\
\hline
\end{tabular}

Source: authors, based on Flipse et al. (2013). 
research, financial, organizational, management tasks (Table 2). During our interactions, we endeavored to identify the Hungarian features that characterize the innovation process and we also raised questions concerning the dimensions of RRI.

We followed nearly all the STIR guidelines introduced in Section 3. Compared to the original pilot study of Fisher et al. (2006), however, we made some changes in order to more precisely understand the thinking and behavioral styles of the researchers. The first modification was to place questions into the pre- and poststudy interviews that focus on the innovation environment's specialties of the investigated country. While Fisher (2007) and Schuurbiers (2011) examined the decision modulators from social and technical perspective, Flipse and his co-authors (2013) integrated economic perspective as a third aspect. We also assume that economic aspects might be necessary for researches in academic environment, too, especially in the case of the "typical" Eastern European research departments, which work with strict budget and are mainly underfinanced. Therefore, we also concluded that it is worth integrating economic aspects in our STIR-discussions and interviews. Following the comprehension of the details of research, the STIR-investigator could ask more targeted questions based on the protocol.

\subsection{Examples of unstructured interactions and learning during the research}

\subsubsection{Site 1}

The pre-study interviews showed that the interviewees were completely unfamiliar with RRI, but in their own interpretation they understood both its content and scope, albeit in relatively narrow terms. Broader societal aspects appeared in the definition provided by only one of the controls. The pre-study interviews also indicated that the interviewees follow the best practices and established rules closely; they do not deviate from them. Furthermore, they do not have work contact with other natural scientists and they do not see the point in involving other professionals (e.g. social scientists) in their decisions and R\&D activities.

Regarding the observation phase, the participating scientists understood the elements and dimensions of responsible innovation due to their subsequent interactions with the STIR investigator. However, topics pertaining both to the innovation process and to the socio-ethical regulation of research and innovation required the collaborators to spend additional time in discussion. Additional time was taken for discussion because, in one case, although participants insisted on best methods and practices for animal testing, they were at first unable to provide a rationale for their practices; moreover, they did not initially see the potential relevance of reflecting on the purpose of the best practices or on additional consider- 
ations related to the issues they were meant to address. This led the collaborators to discuss whether it was necessary for the animals (rats) to be sacrificed after an experiment has been performed or whether there was a theoretical justification for releasing them into the natural environment. In addition to the strict rules of ethical permission for these kinds of experiments, an interesting question arose from the discussion: what is the optimal point of view from a societal standpoint? Given that researchers provide high-quality living conditions for these animals, which can be supported by statistical data (since more money is spent on their living conditions than most Hungarian families have to live on a monthly basis), would the release of the rats be seen socially as undesirable because it would lead to a proliferation of rats? Or would it be acceptable to kill the animals if they have simply fulfilled the purpose for which they had been bred?

We find it of interest that some topics required additional time to be discussed in comparison to similar discussions in developed countries - a fact that we found to be owing to the socialization environment bearing on the distinct innovation setting and its culture. We also find it interesting that with additional discussion, participants became more curious and willing to engage in such considerations about the broader societal context of their research, even though they initially resisted the idea of doing so.

During the course of the STIR interactions, we documented several cases in which participants came to recognize broader societal dimensions of their work (e.g., "Uh, I have not been thinking about this so far, but it is an important aspect"). In several cases, these instances were followed by unstructured interactions during which the investigator made suggestions based on his own expertise. We classify these as instances of enhanced reflexive awareness and group them into four general categories:

1. Ethical issues. One case occurred when the collaborators were discussing the stage of research in which the participant (P1) conducts pathology. Although this experimental phase is also governed by strict ethical permissions, this part of his research also raised additional considerations that were not covered by the ethical permissions and were discussed in accordance with the RRI key of "compliance with the highest ethical standards." Since modeling is common in social sciences, the STIR investigator suggested that the pathological experiment might be substituted with a model (which could, in theory, be physical or computational). P1 had not considered this idea before and stated that "the suggestion seems to be a good idea in theory" although there was no guarantee it would work. This example suggests that scholars and professionals from outside the field of the sciences can, under certain conditions, be seen by scientists as helpful for broadening research thinking and practices. 
2. Long-term side effects. It is clear from the interactions that the researchers had not been thinking about long-term side effects. It was an interesting and significant chapter of the interactions for the collaborators to jointly consider the theoretical possibility for unintended uses of their research results (including the potential for uses that might be seen as harmful from a societal point of view). This line of inquiry developed from the question of what might happen if the research results fell into "wrong hands"? It is likely that the consideration of these concrete examples had the biggest effect on the researchers, who were initially surprised by the question ("Uh, I have not been thinking about this [the unintended possible long-term side effects of their research] so far") and afterwards engaged in what appeared to be deep thought about their answers.

3. Effective time management. After the idea of time frames arose in the discussions, this quickly led to the topic of efficient time management. The STIR investigator suggested that conceptual planning can lead to time saving. P1 found this conception very useful, and stated he would apply it in the future. "This is a really good idea, I have not thought about it [time management]. I will try it" (P1). P1 also recognized that given his sufficient research activity, it was worthwhile to involve students for his own relief; in contrast, P2 postponed this opportunity, choosing instead to perform all research tasks on his own. During our interactions we discussed the importance of effective time management, agreeing that a routine task that does not require special expertise (such as washing test tubes) might be handed over and that, by concentrating more time on the research itself rather than on its supporting activities, research efficiency might be increased through delegation.

4. Science communication. Researchers did not initially recognize the role that science communication can play in research and innovation. During the course of the study, however, researchers not only came to recognize these factors, they also came to see their own roles in the broader process: "wow, if I actually provide the most important message about the research in a language that civil society actors can appreciate, they might really accept it" (P1). This consideration was also discussed in relation to grant applications, in which enlightening the reviewers about the importance of the research plan as well as other aspects of proposed research might add value and contribute to a competitive advantage in comparison with other applicants.

\subsubsection{Site 2}

In contrast to Site 1, we observed only minimal learning and related outcomes on the part of the Site 2's high-interaction participants for several weeks. At the same time, we observed higher reflexive awareness in the pre-study interviews and interactions during the protocol exercises in comparison with pilot 1 . For instance, 
at times, we had the feeling that we were speaking with a social scientist and not a typical Hungarian natural scientist. We endeavored to discover the reason for this marked difference, which was arguably the most significant finding of study 2.

During the study, only the following two cases occurred in which researchers displayed an increase in reflexive awareness (e.g., expressed along the lines of 'Uh, I have not been thinking about this, but it is important'):

1. Negative effects of innovation. Neither researcher participating in study 2 claims to have thought about the possibility of negative or undesirable side effects of their research prior to the STIR study. In hindsight, we can observe clear and significant instances of such recognition; however, these were not as striking as the instances in Site 1.

2. Effective time management. The question of effective time management emerged in connection with the Site 2 study as well. Nevertheless, not as sharply as in the case of the pilot 1 : the researchers spend approximately $10-20 \%$ of their time on routine tasks (washing test tubes, cleaning flasks, polishing materials, etc.), which do not require any special expertise. Saving this time, theoretically would mean increased capacity to test more materials in order to find the most adequate one (in this case for $\mathrm{CO}_{2}$ reduction). In the course of the STIR interactions we observed an increased recognition on the part of the researchers of the temporal economy in which they were embedded, followed by the acknowledgement that more efficient time management could be achieved with decreasing the amount of the background-tasks. Interestingly, however, the participants in study Site 2 nevertheless decided to continue performing the routine tasks in question, which they considered to be an integral part of their job.

Similarly to Site 1, the participants found it beneficial to participate in the present research. As P5 highlighted, several topics had been discussed that the researchers in this group had not been considering previously (e.g. the possible negative or undesirable use of his research results in the future, effective work organization, science communication). P5 felt the conversations were useful, because the methodology raised his/her attention to the fact that it is worth thinking about the possibility of performing tasks differently, for example "think[ing] through the experimental plan even more carefully, so any mistakes would be visible and in this way the costs would be lower." According to P6, grouping his/her knowledge and organizing his/her thoughts using the STIR decision protocol was useful. Especially in the case of P6, frequent statements such as "I consider it the same way, my opinion hasn't changed, but now I consider it in a more conscious and more reasonable way" were observed. It can be concluded that, in case of all the Site 2 participants, the main outcome of the research was that during their work the application of social considerations became more conscious. In other words, while prior to the STIR activities Site 2 
participants tacitly integrated social considerations into their decisions (de facto modulation), by the end of the project they were more explicitly aware of these social aspects of their decisions and were better able to identify them as such (reflexive modulation).

\section{RESULTS}

\subsection{Main results of the 12-week laboratory engagements}

STIR interactions were correlated to changes in reflexive learning, value deliberation, and practical adjustments on the part of participants. By the end of the $12^{\text {th }}$ week, participant awareness at both sites 1 and 2 had been enhanced, as evident in changing conceptions of RRI and socio-technical collaboration, and greater decision awareness. For example, in the post-study interview the initially tight interpretations of RRI were substituted with a more detailed explanations of the concept (Table 3 ).

Table 3. Pre- and post-study changes in conceptions of responsible innovation

\begin{tabular}{l|l}
\hline Q & $\begin{array}{l}\text { Have you ever heard of responsible innovation? And what do you think it means? } \\
\text { How do you interpret the concept of responsible innovation? } \\
\text { P1 (Site 1) }\end{array}$ \\
\hline Pre-study & $\begin{array}{l}\text { I have never heard of responsible innovation before. My interpretation would be } \\
\text { that in the course of our employment public funds should be used in accordance } \\
\text { with proper ethical standards, they should not be wasted, and we should take } \\
\text { responsibility for our decisions... Researchers must engage in responsible conduct, } \\
\text { they should not come up with partial solutions but work on the actual project until } \\
\text { they arrive at the best result possible. }\end{array}$ \\
\hline Post-study & $\begin{array}{l}\text { More social scientific aspects (social, economic) should be included in the innova- } \\
\text { tion process, aspects that people do not encounter on a day-to-day basis. }\end{array}$ \\
\hline Pre-study & $\begin{array}{l}\text { P2 (Site 1) } \\
\text { Being unfamiliar with this concept, I think it means that during innovative activi- } \\
\text { way. }\end{array}$ \\
\hline Post-study & $\begin{array}{l}\text { When producing something new, we have to take into consideration the social, } \\
\text { ethical, economic concerns our project would entail, even in the brainstorming } \\
\text { phase, and we should consider our decisions accordingly. }\end{array}$ \\
\hline Pre-study & P6 (Site 2) \\
\hline Post-study & $\begin{array}{l}\text { I don't know exactly, I will continue to connect it with sustainability, but I can } \\
\text { organize the most important elements of it in my head now. }\end{array}$ \\
\hline
\end{tabular}

Source: authors 
Furthermore, the participants initially stated that there is no need for interactions between natural and social scientists; however, by the end of the observation period, there was a considerable change in the opinion of one participant (Table 4). According to P1, it makes sense to increase interactions between social

Table 4. Pre- and post-study changes in conceptions of socio-technical integration

\begin{tabular}{|c|c|}
\hline \multirow[t]{2}{*}{ Q } & $\begin{array}{l}\text { What could you or the research team do in order to integrate social and ethical } \\
\text { consideration into R\&D activities? }\end{array}$ \\
\hline & P1 (Site 1) \\
\hline Pre-study & At the later stages of the project the general public should be informed of it. \\
\hline \multirow[t]{2}{*}{ Post-study } & $\begin{array}{l}\text { Social aspects do not have to be validated on a weekly basis, but I think some mini } \\
\text { seminars would be necessary, mainly in the field of economics, since the research- } \\
\text { ers do not pursue such studies (for example studies related to efficiency improve- } \\
\text { ment and optimization). This would also be useful for catching up with the more } \\
\text { developed research teams of the west. In other words, it is needed. }\end{array}$ \\
\hline & P5 (Site 2) \\
\hline Pre-study & $\begin{array}{l}\text { As I see it, a person in a leading position can answer this question more properly. } \\
\text { I should have more insight into the social studies to be able to answer this question. }\end{array}$ \\
\hline Post-study & $\begin{array}{l}\text { It could be worth reading not only strictly professional articles [in one's own field], } \\
\text { but also to be more well-read in other study fields. Furthermore, it would also be } \\
\text { worth sitting down with other study fields' researchers in each phase and talking } \\
\text { with them. Not in every small step, but when a certain research reached a given } \\
\text { level or phase [emphasis added]. }\end{array}$ \\
\hline \multirow[t]{2}{*}{ Q } & $\begin{array}{l}\text { What kind of social and ethical considerations are taken into account in the course } \\
\text { of the R\&D activity? }\end{array}$ \\
\hline & P5 (Site 2) \\
\hline Pre-study & $\begin{array}{l}\text { The whole topic is good for the society in the long term, but my daily work has no } \\
\text { effect on it. I have not thought about the ethical considerations so far and right now } \\
\text { I cannot say anything about it. }\end{array}$ \\
\hline Post-study & $\begin{array}{l}\text { Social: from the point of view of society, we conduct such research that can be } \\
\text { beneficial to the whole society; moreover, to reduce contamination in the air. } \\
\text { Ethical: when writing an article I write everything honestly and not just emphasiz- } \\
\text { ing the pieces of information which are favourable for me. Furthermore, we work } \\
\text { hard to choose solutions that are inexpensive and not poisonous. }\end{array}$ \\
\hline \multirow[t]{2}{*}{ Q } & $\begin{array}{l}\text { Do you think it would be productive to increase the rate of interactions between } \\
\text { natural and social scientists? }\end{array}$ \\
\hline & P1 (Site 1) \\
\hline Pre-study & $\begin{array}{l}\text { I do not think this rate should be increased in terms of daily decision making proto- } \\
\text { cols. In some cases though discussions could be important to ease the psychological } \\
\text { pressure, but not in the course of daily decisions. }\end{array}$ \\
\hline \multirow[t]{2}{*}{ Post-study } & It would be pointless on a weekly basis, but some mini seminars could be advisable. \\
\hline & P2 (Site 1) \\
\hline Pre-study & $\begin{array}{l}\text { Discussions with non-professionals are constructive and stimulating, since it is hard } \\
\text { to stay motivated after months of unsuccessful research. As far as researches are } \\
\text { concerned, I do not think the increase in the rate would be of any use. }\end{array}$ \\
\hline Post-study & I cannot say with certainty that it would be absolutely necessary for my work. \\
\hline
\end{tabular}

Source: authors 
and natural scientists. He gave specific examples (mini seminars), in which multi-disciplinary colleagues can obtain and exchange information about the nature of social aspects of science and innovation, since the scientists in his group are only engaged in their own research topics (albeit at a world-class level) and thus broadening their horizons would be beneficial.

According to the participants' opinion, it was beneficial for them to participate in this research. P1 highlighted that several topics had been discussed, which he had not considered previously (e.g. the possible negative use of his research results in the future, effective work organization, science marketing). P2 found the research interesting because it enabled him to prepare for questions that stakeholders and others who are not representatives of the profession would raise, and this is not negligible regarding grants and marketing. As a conclusion, in the case of both participants the main output of the research was broadening their horizon with the integration of social science aspects into natural science ways of thinking.

By the end of the twelve-week participant-observation period both high interaction participants of Site 1 were well aware of their decisions, while at the beginning one of the participants believed he did not make decisions at all. Through the interactions, they became familiar with their own decisions and their potential importance in influencing research outcomes. Interestingly, as their decisionmaking awareness increased, the ad hoc nature of their work decreased. The positive change was especially noticeable in the case of $\mathrm{P} 2$. Towards the end of the research it was him who described the most important stages of his decision making process: "One of my decisions of this kind was when to euthanize animals marked no longer valuable, whether to delay the euthanasia or not. Following the preparation phase, I had to decide which animal would be in the control group and which would take part in the experiment." A further significant result in connection with decision-making is that after having reflected on the process they could identify previous decisions where now they would prefer to adopt a different solution in contrast with the original one. Taking his previous decisions into account, one of the researchers realized that in certain cases he could have acted in a different way. "If I had acted differently, I would be 2-3 months in advance now. If I had operated on the animals at the start, and if I had set the system according to the data obtained from animals already operated on, not according to the old records and data, a lot of problems would have surfaced in time. The solution could have been either satisfactory, or just the opposite." It has to be noted at this point that P2's answer is a clear proof of his evidence-based way of thinking. Discussions conducted with both participating researchers of pilot 1 showed a considerable improvement in their open-mindedness, their decisionmaking awareness, as well as their de facto and reflexive learning ability. During 
the interactive monitoring period the decision-making process of both researchers changed in a rather refined way, as they gradually provided their decisions with a novel framework.

Comparing the two researchers of pilot 1, we can say that $\mathrm{P} 1$ reached the phase of deliberate modulation through the discussion of several topics, and in the case of $\mathrm{P} 2$ we only discovered the presence of de facto and reflexive modulation. P1 gathered some knowledge in social science that presumably formed his thinking and opinion despite the fact that the researcher denied it. P2 did not gather knowledge in areas like this, so the aspects related to social sciences are missing from their thinking, the researcher has a typical mindset that can be connected to natural sciences. Several changes have been observed in the practice in pilot 1 (Table 5) and in pilot 2 (Table 6).

Table 5. Examples of the modulations observed by the researchers in pilot1

\begin{tabular}{|c|c|c|}
\hline \multicolumn{2}{|c|}{ Modulation } & Example \\
\hline \multirow{3}{*}{ P1 } & De facto & $\begin{array}{l}\text { P1 claims in an initial conversation that his research has positive } \\
\text { consequences }\end{array}$ \\
\hline & Reflexive & $\begin{array}{l}\text { After a few more questions, P1 realizes there are possible negative conse- } \\
\text { quences of his experiments, furthermore, he starts to identify several specific } \\
\text { examples including unauthorized remote access to human brain functions. }\end{array}$ \\
\hline & Deliberate & $\begin{array}{l}\text { P1 becomes very concerned and interested in addressing this but feels there is } \\
\text { nothing he can do since the project has already begun, however, he strongly } \\
\text { expresses the intention to reflect on and control for negative consequences at } \\
\text { the beginning of his next research project. }\end{array}$ \\
\hline \multirow{3}{*}{ P1 } & De facto & $\begin{array}{l}\text { P1 states in an initial conversation that the number of rats used for research } \\
\text { purposes is optimal. }\end{array}$ \\
\hline & Reflexive & $\begin{array}{l}\text { In the following week P1 realizes that in the case of short-term experiments } \\
\text { and under certain considerations the number of laboratory rats can gener- } \\
\text { ally be decreased. He examines the possibilities how the experiment can be } \\
\text { redesigned in order to use a lower number of animals, and can assess the } \\
\text { associated cost. }\end{array}$ \\
\hline & Deliberate & $\begin{array}{l}\text { P1 becomes very concerned and interested in addressing this and he strongly } \\
\text { expresses the intention to reflect on and control for this fact when planning } \\
\text { a research project: he will takes this consideration into account at every } \\
\text { stage of the strategic, operative, and tactical decision making, and aims at } \\
\text { sacrificing the least possible lives. }\end{array}$ \\
\hline \multirow{3}{*}{ P1 } & De facto & P1 claims in an early-stage conversation that his time is optimally used. \\
\hline & Reflexive & $\begin{array}{l}\text { After exploring his initial statement P1 realizes the inefficiency of his re- } \\
\text { search activity in terms of time management. P1 accepts time-frame manage- } \\
\text { ment to solve this problem. . }\end{array}$ \\
\hline & Deliberate & $\begin{array}{l}\text { At the end of the STIR project, when arriving at strategic, operative, and } \\
\text { tactical daily decisions he remembered this solution and adopted it in order to } \\
\text { carry out an effective time management. }\end{array}$ \\
\hline
\end{tabular}


Table 5. continued

\begin{tabular}{l|l|l}
\hline \multicolumn{2}{l|}{ Modulation } & Example \\
\hline \multirow{4}{*}{ P2 } & De facto & P2 claims in an early-stage conversation that his time is optimally used. \\
\cline { 2 - 3 } & Reflexive & $\begin{array}{l}\text { Some weeks later P2 realizes the inefficiency of his time management as he } \\
\text { undertakes more tasks than he can cope with. }\end{array}$ \\
\cline { 2 - 3 } Peliberate & - \\
\hline \multirow{4}{*}{ De facto } & $\begin{array}{l}\text { P2 claims in an initial conversation that his research has positive conse- } \\
\text { quences }\end{array}$ \\
\cline { 2 - 3 } & Reflexive & $\begin{array}{l}\text { After a few more questions, P2 realizes the possible negative applications } \\
\text { of his research activity. He can come up with alternatives regarding } \\
\text { what the research results could be used for in a negative way. }\end{array}$ \\
\cline { 2 - 3 } & Deliberate & - \\
\hline
\end{tabular}

Source: authors

Table 6. Examples of the modulations observed by the researchers in pilot 2

\begin{tabular}{l|l|l}
\hline \multicolumn{2}{l|}{ Modulation } & Example \\
\hline \multicolumn{1}{l}{ P5, } & De facto & $\begin{array}{l}\text { P5 and P6 say at the beginning of the STIR project that their research has } \\
\text { positive consequences, since they plan the research to be socially beneficial. }\end{array}$ \\
\cline { 2 - 3 } P6 & $\begin{array}{l}\text { After long conversations, they can specify some negative consequences, but } \\
\text { think these thoughts are really abstract and can't happen based on the current } \\
\text { level of science. }\end{array}$ \\
\cline { 2 - 3 } & Deliberate & $\begin{array}{l}\text { After subjecting their initial thought to rigorous scrutiny, the researchers are } \\
\text { more confident that the research is well-planned and in view of this they will } \\
\text { plan the next experiment even more consciously. }\end{array}$ \\
\hline \multirow{4}{*}{ P5 } & $\begin{array}{l}\text { In the early stages of the conversations, P5 says that in the course of her job } \\
\text { Reflexive } \\
\text { solutions and approaches. }\end{array}$ \\
\cline { 2 - 3 } & $\begin{array}{l}\text { After a few weeks, P5 realizes that it makes sense to look at the validated } \\
\text { methods with a critical eye, and search new solutions, since that can bring } \\
\text { real novelty. }\end{array}$ \\
\hline Deliberate & $\begin{array}{l}\text { During the replication of an experiment, when she came to a decision point } \\
\text { that involved multiple experimental design choices (reactants, temperature, } \\
\text { etc.), she remembered the importance of the critical approach and started to } \\
\text { think about alternative options of each of these choices as well. }\end{array}$ \\
\hline
\end{tabular}

Source: authors

\subsection{Differences between Sites 1 and 2 and Role of the Laboratory Director}

In the case of pilot 2 , similarly to pilot 1 , discussions conducted with both participating researchers showed an improvement in their open-mindedness, their decision-making awareness, as well as their de facto and reflexive learning ability. In particular cases, the way of thinking of the participants has changed noticeably. However, most frequently there was no change under the pressure of 
modulation, but the level of consciousness has raised, their thoughts have been organised into a clear system. It is also visible that we observe minimal heuristical recognition and only a few relevant changes in the decisions of the participating researchers. While during pilot 1 , we experienced de facto and/or reflexive learning processes week after week, we observed minimal learning and other effects on the high-interaction participants during the second STIR study for several weeks (Figure 2). At the same time, we observed a higher level of reflexive awareness, first at the beginning in the pre-study interviews, then in interactions during the protocol exercises.

Initially we did not understand the cause of this phenomenon, but we sought the possible explanation. Besides being a chemist, the principal investigator of the pilot 2 is a graduated economist, therefore he already has been having the potential to shape the way of thinking of his research group in an unconscious way. Thus, we assume that during the past years social science thoughts got into researchers' head by the principal investigator, in a way that they have not recognised directly. They have learned this mentality through daily routine tasks, and it has got into their subconscious. Based on all these facts, the principal investigator is carrying a quasi long-term STIR project himself in his research group, moreover he is the embodiment of the STIR. We tested our hypothesis in two ways:

1. During the STIR interaction, we touched upon the topic of lab meetings. We were interested in how much the principal investigator touches upon the top-

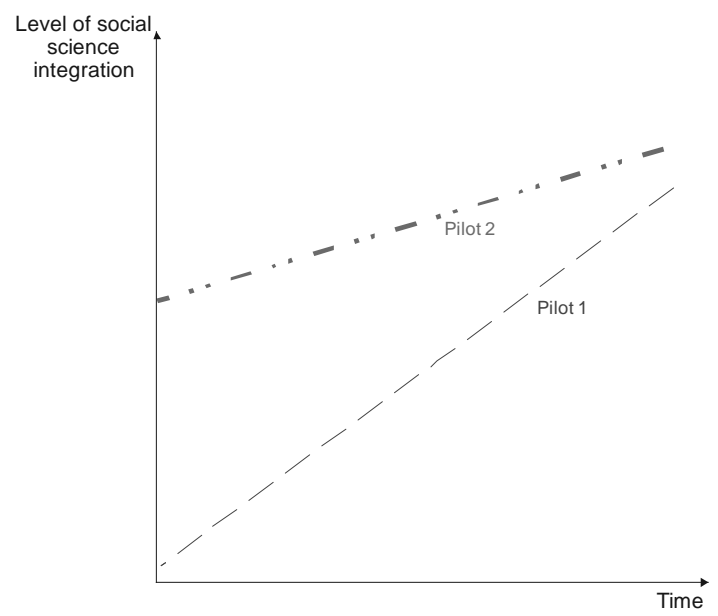

Figure 2. Idealised learning trajectory in the two pilots

Note: the actual pathway is not significant, only the starting and the end point

Source: authors 
ics that we count as social science topics. According to P5 and P6, they hold lab meetings weekly and in many cases, they discuss those aspects of the topic, which are similar to the social aspects that were revealed in the STIR project. However, we need to highlight that the STIR interactions pointed out this recognition, as well.

2. We conducted an in-depth interview with the principal investigator. Our aim was to find out how important is for him the social science integration into natural science research. He/she told us, that this is why he/she applied to economics studies as a graduated chemist because he/she finds it especially important to integrate social science thoughts into his/her thinking. As an MA graduated economist principal investigator he/she strives to hand his/her knowledge over to his/her researchers.

At this point, it is important to mention that in the pre-study interview P5 and P6 gave $0 \%$ to the question "Please explain to me your perception of the value, if any, of interactions between natural and human scientists in the laboratory during research and development activities." However, in the post-study interview both P5 and P6 expressed that if the question would be "Please explain to me your perception of the value, if any, of the social science thinking during the research group's work.", they would give $10-20 \%$ at the end of the study.

Based on the above mentioned, if we expand the STIR methodology to carry out the STIR project not only with researchers but also with principal investigators, what is more, if we can train them in the STIR methodology so they can carry out STIR in their research group, then perhaps the effect can be more sustainable. The duration of this PI-STIR is implicitly much longer, and the effects would appear later than with the present methodology.

Our findings may have long-term impacts on the research process. As we discussed above, a STIR study enables to improve behaviors, practices, design and research pathways, but it also affects skill development, learning, human capital, on the one hand, and increased trust and social capital between different (social science and natural science) disciplines, on the other hand. If the discourse between the different disciplines could start owing to the STIR study, the incorporation of the RRI would be more effective.

\subsection{General findings for STIR in an Eastern European setting}

The pilot projects were implemented in research groups financed publicly. Therefore, the following results we mention are mainly true for these kind of research projects. We assume that STIR would have different results in the case of private research groups. The reflexive modulation can be observed in empirical stud- 
ies conducted in developed countries but current study shows that STIR has demonstrable but limited effectiveness in an Eastern European setting. The tools of STIR can be utilized as in developed areas, however, there may be a need of a methodology-development to reach the level of deliberate modulation. The examples of reflexive learning and changes in practice tend to be based on firstorder reflexivity, which involves more efficiently accomplishing predetermined goals and values, rather than second-order reflexivity, which involves questioning predetermined goals and values. However, the application of the method in the transition countries is influenced by special features:

1. The context in which the researchers were socialized (ex-Soviet environment) influenced their decisions.

2. Researchers show a limited understanding of the broader innovation system.

3. Researchers only recognize direct costs and benefits.

4. All the above mentioned changes required an inordinate amount of time discussing basic social, ethical and economic issues of science and technology that would be more familiar to scientists in developed countries.

Thus the RRI readiness of these countries is much lower than of the developed countries, so the introduction of RRI should start on the ground level in many transition countries. We suggest the following:

1. Extension of the examination period during the STIR methodology. A possible solution is that the examination period would be preceded by a Step Zero, which targets to balance these deficiencies.

2. Integration of economic aspects during the introduction of RRI ("internalization of externalities"). In initial phases of RRI introduction, public authorities and business support organizations should consider providing funding tools to support RRI introduction.

3. Extension of the STIR methodology. The STIR project should be carried out not only with researchers but also with principal investigators, or we can train them to the STIR methodology so they can carry out the STIR in their research group, which could result in a more sustainable condition.

4. Improving the knowledge on the keys of RRI and the abilities of the STIRinvestigator or employing more STIR-investigator of different fields.

\section{CONCLUSIONS}

In this study, we tried to identify how the integration of the responsibility dimension of responsible innovation activity can be realized, and what special challenges we have to face in the Hungarian innovational environment. We conducted two empirical pilot researches based on the STIR methodology in natural science lab- 
oratories at the University of Szeged. The characteristics that were identified by previous projects concluded in developed countries could also be identified in the Hungarian innovation environment. We found relevant changes in the researchers' thinking and behavior. Reflexive learning was identified as well as value deliberation, furthermore, the awareness regarding their decisions increased and the ad hoc characteristics of their work decreased. We identified the specifications of the Hungarian innovation system, which influence the possibilities of the implementation of responsible innovation: support-driven innovations, obsolete research and development infrastructure, daily survival problems of innovators, the importance of informal connections.

In summary, we realized that STIR is able to support reflexive learning and practical changes in the characteristics of the Hungarian (and to some extent of the Eastern European) environment but the method should be adapted to fit the Eastern characteristics:

- Lab-level: Follow the general process of an STIR study, but extend the examination period by an initial preparatory phase.

- Policy-level: Work with policy makers to create incentives for researchers to be more aware of and responsive to broader and longer-term societal dimensions of innovation.

However, there are some limitations of the research and numerous questions were raised which can be a basis for further research. Results of the STIR projects highly depend on the skills of the embedded humanist. It is clear that if he or she is an economist, the economic issues will be emphasized during the on-site research, while if the humanist is an ethical expert, the ethical concerns of the research would be in the focus. Furthermore, our two pilots were employed in South-East Hungary, however, it is shown that the innovation system is a bit different in the surroundings of Budapest and in Western Hungary. In order to be able to conclude more general findings, it is worth working in labs in other parts of Hungary, too. In the long-run, it would be also useful to compare the results of STIR-pilots conducted in the neighboring countries of Hungary. Moreover, the long-term impacts also should be analyzed and re-visits to the STIR-labs are required.

\section{REFERENCES}

Aerni, P. (2005): Stakeholder Attitudes Towards the Risks and Benefits of Genetically Modified Crops in South Africa. Environmental Science \& Policy 8(5): 464-476.

Apak, S. - Atay, E. (2015): Global Competitiveness in the EU through Green Innovation Technologies and Knowledge Production. Procedia - Social and Behavioral Sciences 181: 207-217.

Barben, D. - Fisher, E. - Selin, C. - Guston, D. H. (2008). Anticipatory Governance of Nanotechnology: Foresight, Engagement, and Integration. In: Hackett, E. J. - Amsterdamska, O. - Lynch, 
M. E. - Wajcman, J. (wds.): New Handbook of Science and Technology Studies. Boston: MIT Press, pp. 979-1000.

Bennet, I. - Sarewitz, D. (2006): Too Little, Too Late? Research Policies on the Societal Implications of Nanotechnology in the United States. Science as Culture 15(4): 309-326.

Bien, H.-J - Ben, T.-M. - Wang, K.-F. (2014): Trust Relationships within R\&D Networks: A Case Study from the Biotechnological Industry. Innovation: Management, Policy \& Practice 16(3): 354-373.

Buzás, N. - Lukovics, M. (2015): A felelősségteljes innovációról [Responsible Innovation]. Közgazdasági Szemle 62(4): 438-456.

Buzás, N. - Lukovics, M. (2016): Southern European Perspectives. In: von Schomberg, R. (ed.): Handbook of Responsible Innovation - a Global Resource. Edgar Elgar Publishing.

Chorus, C. - van Wee, B. - Zwart, S. (2012): TPM Catalogue. Concepts, Theories, Methods. Delft: Delft University of Technology.

Ciocanel, A. B. - Pavelescu, F. M. (2015): Innovation and Competitiveness in European Context. Procedia Economics and Finance 32: 728-737.

Dosi, G. - Grazzi, M. - Moschella, M. (2015): Technology and Costs in International Competitiveness: From Countries and Sectors to Firms. Research Policy 44(10): 1795-1814.

EC (2016): European Innovation Scoreboard. Brussels: European Commission.

Edquist, C. (2005): Systems of Innovation Approaches. Their Emergence and Characteristics. In: Edquist, C. (ed): Systems of Innovation. Technologies, Institutions and Organizations. London - New York: Routledge, pp. 1-35.

Eurobarometer (2011): Consumer Understanding of Labels and the Safe use of Chemicals. Report, Special Eurobarometer 360.

Eurobarometer (2013): Responsible Research and Innovation (RRI), Science and Technology. Report, Special Eurobarometer 401 .

Farkas, B. (2011): The Central and Eastern European Model of Capitalism. Post-Communist Economies 23(1): 15-34.

Farkas, B. (2016): Models of Capitalism in the European Union: Post-crisis Perspectives. London: Palgrave Macmillan.

Fisher, E. (2007): Integrating Science and Society in the Laboratory. Presentation. Center for Integrated Nanotechnologies. Los Alamos National Laboratory. Los Alamos, NM.

Fisher, E. - Mahajan, R. L. - Mitcham, C. (2006): Midstream Modulation of Technology: Governance from Within. Bulletin of Science, Technology and Society 26(6): 485-496.

Fisher, E. - Maricle, G. (2014): Higher-level Responsiveness? Socio-technical Integration within US and UK Nanotechnology Research Priority Setting. Science and Public Policy, 28 April 2014, 1-14.

Fisher, E. - Schuurbiers, D. (2013): Midstream Modulation. In: Doorn, N. - Schuurbiers, D. - van de Poel, I. - Gorman, M. E. (eds): Opening up the Laboratory: Approaches for Early Engagement with New Technology, Wiley-Blackwell, 97-110.

Fisher, E. - Slade, C. - Anderson, D. - Bozeman, B. (2010): The Public Value of Nanotechnology? Scientometrics 85(1): 29-39.

Fisher, E. - O’Rourke, M. - Kennedy, E. B. - Evans, R. - Gorman, M. - Seager, T.† (2015): Mapping the Integrative Field: Taking Stock of Socio-Technical Collaborations. Journal of Responsible Innovation 2 (1): 39-61.

Flipse, S. M. - van der Sanden, M. C. A. - Osseweijer, P. (2013): Midstream Modulation in Biotechnology Industry: Redefining what is 'Part of the Job' of Researchers in Industry. Science and Engineering Ethics 19(3): 1141-1164. 
Flipse, S. M. - van der Sanden, M. C. A. - Osseweijer, P. (2014): Improving Industrial R\&D Practices with Social and Ethical Aspects: Aligning Key Performance Indicators with Social and Ethical Aspects in Food Technology R\&D. Technological Forecasting and Social Change 85(6): 185-197.

Flipse, S. M. - Vrielink, J. O. - van der Sanden, M. C. (2015): Building Interactive Communication Tools to Support Interdisciplinary Responsible Innovation. Journal of Innovation Management 3(4): 119-133.

Guston, D. H. (2014): Understanding Anticipatory Governance. Social Studies of Science 44(2): 219-243.

Guston, D. H. - Sarewitz, D. (2002): Real-Time Technology Assessment. Technology in Society 24(1-2): 93-109.

Havas, A. - Nyíri, L. (eds.) (2007): A magyar nemzeti innovációs rendszer [The Hungarian Innovation System]. Háttértanulmány az OECD 2007/2008. évi innovációs országjelentése számára. Budapest: NKTH.

Inzelt, A. - Csonka, L. (2014): Responsible Science in Societies. In: Buzás, N. - Lukovics, M. (eds.): Responsible innovation. Szeged: JATEPress, 57-72.

Lengyel, B. - Leydessdorff, L. (2011): Regional Innovation Systems in Hungary: The Failing Synergy at the National Level. Regional Studies 45(5): 677-693.

Lengyel, I. (2009): Knowledge-based Local Economic Development for Enhancing Competitiveness in Lagging Areas of Europe: The Case of the University of Szeged. In: Varga, A. (ed): Universities, Knowledge Transfer and Regional Development: Geography, Entrepreneurship and Policy. Cheltenham-Northampton: Edward Elgar, pp. 322-349.

Lopez, R. - Carrau, J. G. (2002): The GMO Regulation in the EU and the Commercial Conflict with the United States. Paper provided by European Association of Agricultural Economists in its series 2002 International Congress, August 28-31, 2002, Zaragoza, Spain.

Lukovics, M. - Buzás, N. - Huntingford, J. - Chiocca, M. - Bubbolini, G. - Udvari, B. (2016a): Facilitating Responsible Innovation in the South-East European Countries. Journal of Responsible Innovation (under review)

Lukovics, M. - Buzás, N. - Huntingford, J. - Molnár, G. (2016b): Felelősségteljes innováció a Délkelet-európai országokban [Responsible Innovation in Southeast European Countries]. In Lengyel, I. - Nagy, B. (eds): Térségek versenyképessége, intelligens szakosodása és újraiparosodása. Szeged: JATEPress, 62-78.

Macnaghten, P. - Owen, R. - Stilgoe, J. - Wynne, B. - Azevedo, A. - de Campos, A. - Chilvers, J. - Dagnino, R. - di Giulio, G. - Frow, E. - Garvey, B. - Groves, C. - Hartley, S. - Knobel, M. - Kobayashi, E. - Lehtonen, M. - Lezaun, J. - Mello, L. - Monteiro, M. - Pamplona da Costa, J. - Rigolin, C. - Rondani, B. - Staykova, M. - Taddei, R. - Till, C. - Tyfield, D. - Wilford, S. Velho, L. (2014): Responsible Innovation across Borders: Tensions, Paradoxes and Possibilities. Journal of Responsible Innovation 1(2): 191-199.

Martus, B. (2015): Növekedjünk vagy foglalkoztassunk? Az amerikai gazdasági növekedés problémája [Growth or Employment? The Problem of American Economic Growth]. Pénzügyi Szemle 60(2): 254-274.

Nielsen, C. P. - Thierfelder, K. - Robinson, S. (2003): Consumer Preferences and Trade in Genetically Modified Foods. Journal of Policy Modeling 25(8): 777-794.

OECD (2011): Society at a Glance 2011: OECD Social Indicators. Paris: OECD Publishing.

Owen, R. - Baxter, D. - Maynard, T. - Depledge, M. (2009): Beyond Regulation: Risk Pricing and Responsible Innovation. Environmental Science \& Technology 43(18): 6902-6906.

Owen, R. - Macnaghten, P. - Stilgoe, J. (2012): Responsible Research and Innovation: From Science in Society to Science for Society, with Society. Science and Public Policy 39(6): 751-760. 
Panzda, K. - Ellwood, E. (2013): Strategic and Ethical Foundations for Responsible Innovation. Research Policy 42(5): 1112-1125.

Ravesteijn, W. - Liu, Y. - Yan, P. (2015): Responsible Innovation in Port Development: The Rotterdam Maasvlakte 2 and the Dalian Dayao Bay Extension Projects. Water Science \& Technology 72(5): 665-677.

Rip, A. (2005): Technology Assessment as Part of the Co-Evolution of Nanotechnology and Society: the Thrust of the TA Programme in NanoNed. Paper presented to the Conference on Nanotechnology in Science, Economy and Society, Marburg, Germany.

Rodríguez, H. - Fisher, E. - Schuurbiers, D. (2013): Integrating Science and Society in European Framework Programmes: Trends in Project-level Solicitations. Research Policy 42(5): 11261137.

Schomberg, R. von (2012): Prospects for Technology Assessment in a Framework of Responsible Research and Innovation. In: Dusseldorp, M. - Beecroft, R. (eds.): Technikfolgen abschätzen lehren: Bildungspotenziale transdisziplinärer Methoden. Wiesbaden: Springer Vs Verlag Fur Sozialwissenschaften, pp. 39-61.

Schuurbiers, D. (2011): What Happens in the Lab: Applying Midstream Modulation to Enhance Critical Reflection in the Laboratory. Science and Engineering Ethics 17(4): 769-788.

Schuurbiers, D. - Fisher, E. (2009): Lab-scale Intervention. EMBO Reports. Science \& Society Series on Convergence Research 10(5): 424-427.

Setiawan, A. D. - Singh, R. (2015): Responsible Innovation in Practice: The Adaption of Solar PV Telecom Towers in Indonesia. In: Koops, B.-J. - Oosterlaken, I. - Romijn, H. - Swierstra, T. van den Hoven, J. (eds.): Responsible Innovation 2: Concepts, Approaches, and Applications. Switzerland: Springer, pp. 225-244.

Stilgoe, J. - Owen, R. - Macnaghten, P. (2013): Developing a Framework for Responsible Innovation. Research Policy 42(9): 1568-1580.

Sutcliffe, H. (2013): A Report on Responsible Research and Innovation. London: Matter.

Taebi, B. - Correljé, A. - Cuppen, E. - Dignum, M. - Pesch, a U. (2014): Responsible Innovation as an Endorsement of Public Values: The Need for Interdisciplinary Research. Journal of Responsible Innovation 1(1): 118-124.

Tihon, A. - Ingham, M. (2011): The Societal System and Responsible Innovations: Freeing Sustainable Development from a Deadlock. Journal of Innovation Economics 2(8): 11-31.

Várady, J. - Tóth, M. - Fogarasi, J. (2005): Merre tovább? A Magyar vegyipar jövőképe. A Magyar vegyipart érintő szakképzés, felnőttképzés fejlesztésének problémái, lehetőségei [The Future Image of the Hungarian Chemical Industry]. Available: http:/www.vdsz.hu/files/45/22/vegyip szakkepzes.pdf, accessed 4 December 2016)

Vigani, M. - Raimondi, V. - Olper, A. (2010): GMO Regulations, International Trade and the Imperialism of Standards. Paper provided by LICOS - Centre for Institutions and Economic Performance, KU Leuven in its series LICOS Discussion Papers.

Vilmányi, M. (2011): The Relationship Performance in the Field of University-Industrial R and D Cooperation. In: Hetesi, E. - Kürtösi, Zs. (eds.): Diversity of Research at the Szeged Institute of Business Studies. Szeged: JATEPress, pp. 75-95.

Voeten, J. - de Haan, J. - de Groot, G. - Roome, N. (2015): Understanding Responsible Innovation in Small Producers' Clusters in Vietnam through Actor-Network Theory. European Journal of Development Research 27(2): 289-307.

Zouaghi, F. - Sánchez, M. (2016): Has the Global Financial Crisis Had Different Effects on Innovation Performance in the Agri-Food Sector by Comparison to the Rest of the Economy? Trends in Food Science \& Technology 50(4): 230-242. 